\title{
FABRICATION OF SOLAR POWERED ULTRAVIOLET (UV) WATER PURIFIER
}

\author{
N.VENKATESWARA RAO ${ }^{1}$, N.VENKATESH ${ }^{2}$ \& K.I.V VANDANA ${ }^{3}$ \\ ${ }^{1,2}$ UG Students, Department of Mechanical Engineering, PVP Siddhartha Institute of Technology, Vijayawada, AP, India \\ ${ }^{3}$ Assistant professor, Department of Mechanical Engineering, PVP Siddhartha Institute of Technology, Vijayawada, AP, India
}

\begin{abstract}
In this paper an attempt has been made to fabricate an ultraviolet (UV) water purifier. The equipment is designed to utilize solar power for water purification. Water is one of the most vital component in human life cycle. Though $70 \%$ of earth contains water, only $1 \%$ is suitable for drinking. The present work proposes to develop solar powered UV water purifier to get clean water free from Bacteria, Yeast, Mold Spores Algae etc. With the usage of UV rays, the microorganisms are removed. Different types of filters like carbon filter, sediment filter etc are used, apart from UV filter for purification of water to get safe drinking water. Solar power is used to charge a D. C battery connected to the system so that the system works even on a day when sunlight is not available due to clouds. There is a provision for the usage of both A.C and D.C power.
\end{abstract}

KEYWORDS: UV (Ultraviolet), UV Filtration, Solar Power, Solar Charge Controller\& Water purifier

Received: May 25, 2020; Accepted: Jun 15, 2020; Published: Jun 30, 2020; Paper Id.: IJMPERDJUN2020176

\section{INTRODUCTION}

Availability of pure and safe drinking water is the major problem facing by the world in present days. Many countries are suffering with water scarcity. Even though water is available there is no guarantee of purity. Water purification is the process to remove the contaminants from the ground water for the specific purposes. The contaminants like particulate matter, dissolved minerals. Various technologies are available in the market to purify water such as distillation, ion exchange, filtration, RO membrane filtration, ultraviolet (UV) radiation or a combination of more than one technology. The mostly used technology is Reverse Osmosis, where pure water is obtained at a cost of about double the capacity of water are wasted as drain water.Due to poor quality of water and presence of various chemicals, water may cause many diseases. Lead metal can cause brain damage and it is very dangerous to human health. Water may also contain various types of bacteria.Even though there are many technologies available in market, every system requires power supply to purify water.

Shortage of quality drinking water is the main concern in many areasof the world. The populace was expanding day by day and this alarms more prominent requirement for drinking water resources. At the same, with the boundless increase in the population, more pollution is released into the environment and consequently contaminating many rivers, streams and lakes. Polluted water will carry diverse types of water borne ailments. Waterconsumed from unprocessed sources definitely cause severe ailmentsand may lead to even fatality. The water sources that are away from populous areascan carry bacteria and virus making that waterharmful to human wellbeing. Variousparts in the worldrequire a solution to convert their contaminated water in to potable.As scarcity and pollution of water are increasing rapidly, the areas that currently do not need these measures for harmless drinking water mightwant it in the upcomingdays certainly.Personnel or private water purification system provides enough 
safe drinking water tofamilies. It is very difficult to repair natural reservoirs as it is associated with very high costs. World require apromptresolution to this problem.So there is a need for preparing a low cost flexible water purification system and with this system, dangerous water sources now shouldbecome suitable for drinking. And the proposed method was as shown in Figure 1.

\section{LITERATURE REVIEW}

ManojPhalak et al 2017[1] used solar energy to prepare a RO system water purifier model for residential application. The proposed water purifier can be converted in to a portable system. Anil K. Rajvanshi and NoorieRajvanshi et al 2018[2] attempted to fabricate a solar water purifier with low cost which is simple for the benefit of rural households. It does not needany electricity. Aaron Don M. Africa et al 2017[3] discussed that purification of water is vitalparticularly in case of calamities asin calamities most of the people requireslarge amounts of drinking water. Moa Megersa et al 2015[4] explained the employment of plants in purifying wateras described ininscriptions of Egyptians. Deepak Devasagayam et al 2014[5] stated the effectiveness of carbon filters in removing different unwanted organic chemicals from water Paul OnkundiNyangaresi et al 2018 [6] Discussed about the potential benefits of replacement of conventional ultraviolet pressure lamps with the Ultraviolet light emitting diodes for water disinfection. Piyush R. Panditrao et al 2014[7] developed a low cost water filtration \& recycling system. They fallowed a filtration methodwhich is observed in nature and created a reliable \& cost-effective system to clean water. It is well established for domestic purposes. K.M. Johnson et al 2010[8] described microbial disinfection using ultraviolet radiation to filterthe water. Intensity of UV radiation, exposure time and area of exposure are the main parameters in controlling the effectiveness of this process.Mary $\mathrm{H}$. Crawford et al 2005[9] has employed ultraviolet LEDs in the deep water system for water purification. Mr. WadekarAbhijit Narayan et al 2018[10] prepared domestic filters which are first of its Variety. The lack of clean water is a major problem of plagues many areas of the world in today. There are various technologies available in the market such as RO membrane, UV radiation UF filtration.

From the literature survey it was understood that UV filtration gives safe and pure water with out any wastage. Here efforts are expended to makea solar power water purifier. In the most of rural areas power availability is less when compared to urban areas. Without electricity, purification plant cannot be operated. Hence, we can use the solar power for the processing of purifier. It is clean source of electricity and environment friendly.

\section{METHODOLOGY}

\section{Fig.1: STEPS IN PROPOSED WATER PURIFICATION SYSTEM}

The above flow chart in Fig.1. shows the flow of water from the tank to the end purified stage using solar power source. Ultraviolet based water purification method is the most effective way of disinfecting bacteria from the water. Ultraviolet (UV) rays can penetrate through harmful pathogens in water and will destroy illness-causing bacteria and microorganisms by spoiling their genetic DNA core. 


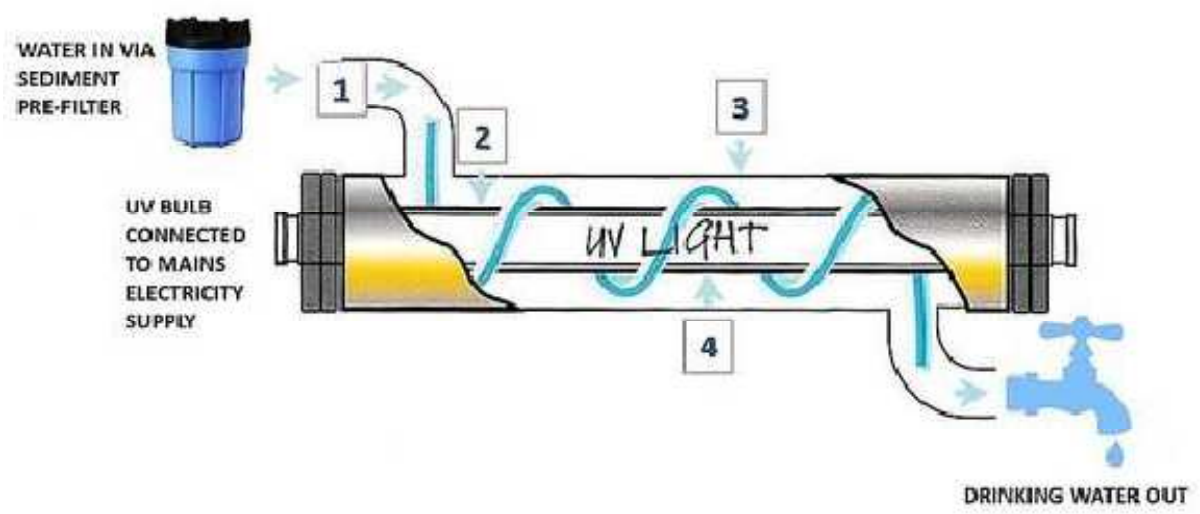

1: sediment Filter 2: carbon Filter 3-Ultrafiltration (UF) 4: Ultraviolet Lamp Filter

Figure 2: Stages of Water Flow.

The system shown in Figure 2 reveals the stages of purification. The impure water first enters the sediment filter. The naked impurities are removed. After that the water enters the carbon filter where the microparticles are removed. Then the water flows through the UV filter where the water is exposed to the UV light rays of optimal wavelength. This impacts the DNA of the micro-organisms there by killing them. This prevents the growth of disease-causing agents. By this the water obtained is fit for drinking.

\section{PRINCIPAL COMPONENTS}

Carbon Filter: Adsorption process is the major principle ofCarbon filtering, andcontaminantspresent in the liquidare to be trapped will be captured by porous structure (of carbon substrate).Because substrate consists of large surface area , it can trap contaminants of water.

Sediment Filter: It is the basic water filtration system and is most common type that is widely used across the world in different applications like residential, industrial and commercial water treatment systems. It works well and removes sediments like sand, rust, slit, dust, heavy metals especially large particles present in water. Generally, a sediment filter is made up of pleated polyester or melts blown polypropylene (PP) with micron size particles ranging from 1 to 100 microns. The micron value indicates the size of the pores present in the filter. Lower microns mean very strong filtration but with slower water filtering rate. Sediment filter is alone used as a point of entry or can be used in combination with othertypes filters to achieve greater filtration. This type of filter is normally employed as a prefilter in water filtration system in residential applications.

Ultra-filtration Filter: Ultra-filtration is a technology which make use of hydrostaticbasedpressure to force the flowing water through a submicron hollow fiber which semipermeable ( 0.01 to 0.5 microns)withUF membrane to filter the most of the living organisms and contaminants in water. The UF membrane ( 0.01 to 0.02 microns) with small microns rating is much capable to filter microscopic contaminants like bacteria, virus and parasites, bacteria, and virusesthough retaining the required essential useful minerals.

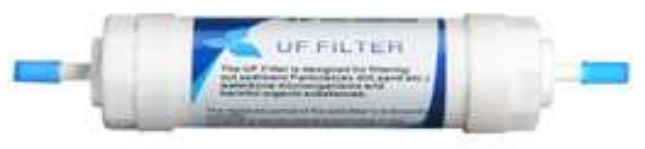

Figure 3: Ultra-Filtration Filter. 


\section{UV LAMP AND WAVELENGTH}

UVC lightsemitultravioletrayswith short wavelengths which are germicidal.Light from these bulbs kills the germs by destructing the nucleic acid of bacteria and microorganisms. Basing on exposure time and intensity dosage can be adjusted. Be sure you know how much ultraviolet light you need before selecting a specific lamp. If you need assistance, feel free to contact our support staff.These lamps are used for variety of things helps very much in eradicating the harmful bacteria. Always wear rubber gloves when cleaning the lamps to protect your hands and keep your skin's natural oils off the lamps and use alcohol only. This will help maximize the lamp's life.

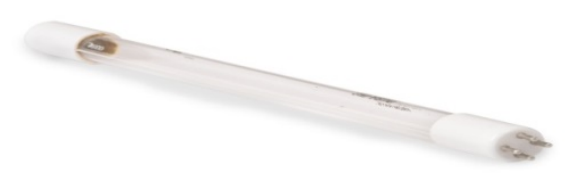

Fig.4: UV Lamp

D.cballast:Ballasts are simple like resistors and available with different varieties of complexity. DC link choke is an electrical device that filters and controls the DC bus voltage and current in a variable frequency drive. The function similarly to AC line reactors, in that they smooth the current flow to the VFD and reduce harmonic distortion on the power line

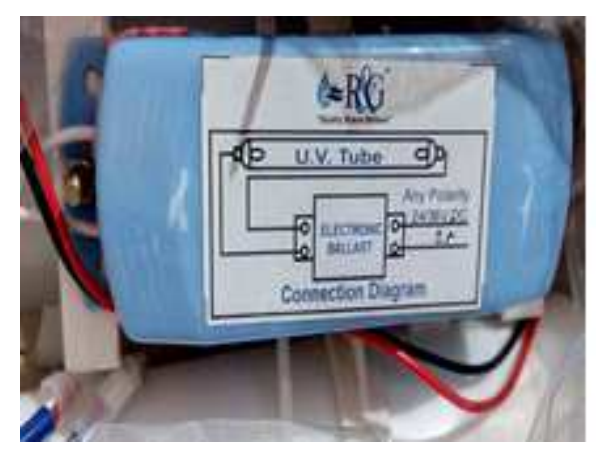

Figure 5: DCBallast.

Solar Panel: Solar panel is of capacity 20watts and voltage 16.5 volts andmaximum current output of 1.21 Amps is used with a tolerance of $2 \%$ module of Photovoltaic cells. ThePhotovoltaic cells are generally connected in series electrically, to a preferred voltage, and in parallel to enhance amperage.

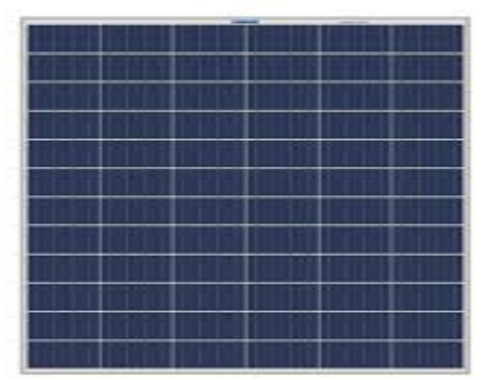

Figure 6: Solar Panel. 
Solar I-V Characteristic:The I-VCharacteristiccurve offerssignificant performance of the process about PV modules. It includes 1.circuit voltage 2. short circuit current 3. maximum rated power 4.maximum current 5.maximum voltage

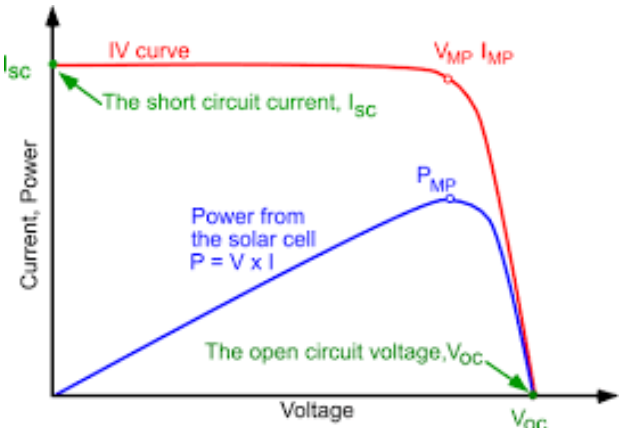

Fig.7: Solar I-V Characteristic

\section{SolarPVCharacteristics}

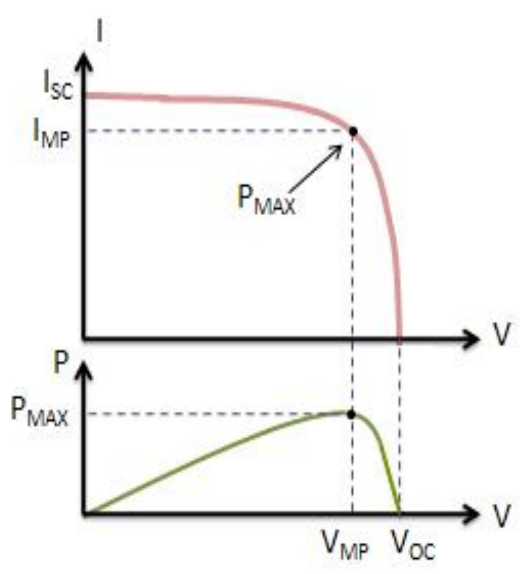

Figure 8: Solar PVCharacteristics.

The maximum power is generated at the maximum voltage and maximum current.

DC Rechargeable Battery: It is a dry type battery which is commonly used in different charging appliances. Within put from solar charge controller.These batteries are group of cells and generate a flow of electrons with chemical reactions in a circuit. Batteries consistof anode, cathode and electrolyte.The connected cathode with anode of a battery in acircuitmakeselectrons to flow in the circuit and come back to the cathode to initiate one more chemical reaction..

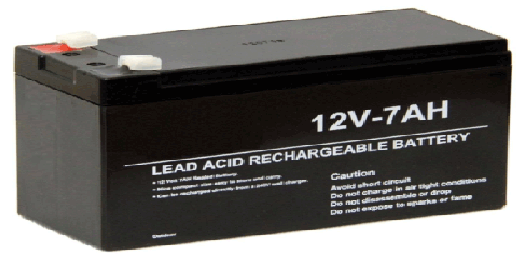

\section{Solar Charge Controller}

Figure 9: DC Rechargeable Battery.

1A charge regulator or controller is basically a current/voltage regulator to keep batteries safe from being overcharged. It regulates both current and voltage that is coming from the panels (solar). 


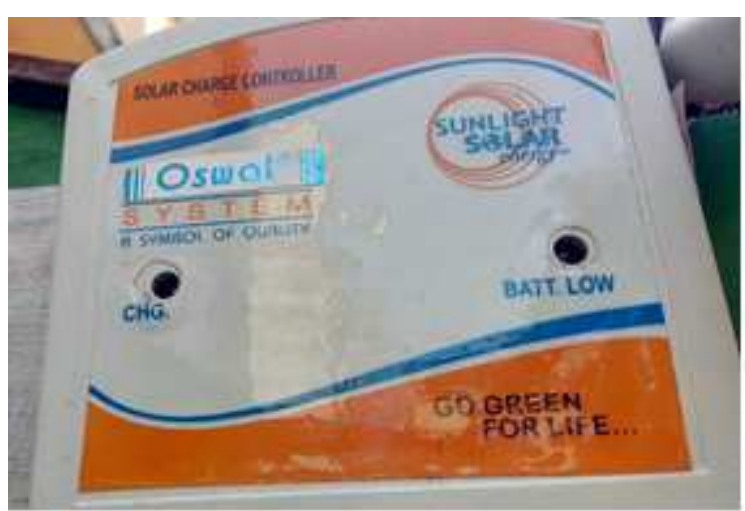

Figure 10: Solar Charge Controller.

Push Fits: push-to-connect orpush-to-connect or Push-to-pull fittings are a variety of simply removed quick connect or compression fitting which allows air or water line which is to be attached with out using tools.

Ball Valve:It is a valve with quarter-turn and having a perforated, hollow and pivoting ballwhich control flow through it.The ball valve out let is $1 / 2$ inch and the inlet is 1 inch.the pressure in the valve can be checked through the opening provided on one side of valve after checking the hole it can be closed with a dummy cap.

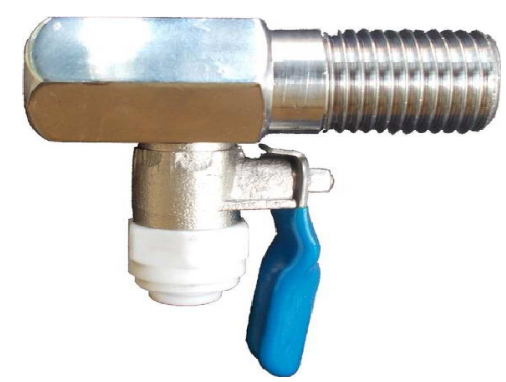

Fig.11: Ball Valve

\section{EXPERIMENTATION}

At first, to remove large sized particulates, sediment filter is employed. Water is made to enter the sediment filter with the filter membrane. Then the water enters the carbon filter, This activated carbon removes pollutantslike organic materials. It also removesodor causing impurities making this water more palatable.From there the water enters the ultra-filtration membrane.Here the process is much similar to process of reverse Osmosis. It uses hydrostatic pressure andforce the waterin to sa semi-permeable membranes. Suspended solutes and solids of higher molecular weight are reserved,whereassolutes and water with less molecular weight are passed through the permeable membrane. From here the water enters the Ultraviolet light filter where the Ultraviolet light of wavelength $240 \mathrm{~nm}$ destroys the micro-organisms. Finally, the pure water comes out through the hoses. The connections are made and the purification system was prepared as shown in Figure 12. 


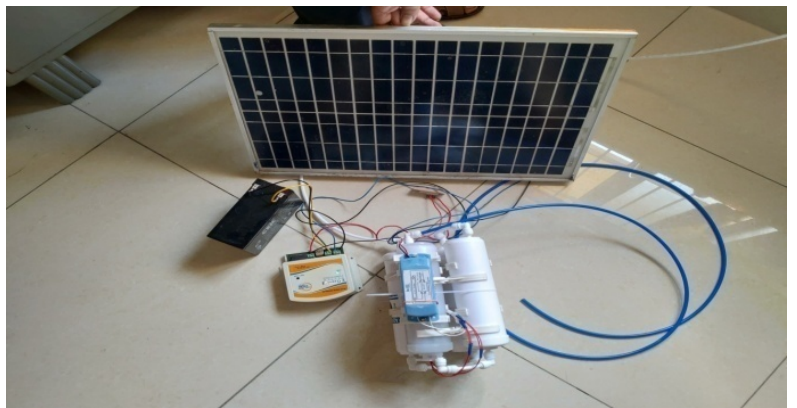

Figure 12: UV Based Proposed Water Purification System.

After the experimentation, the obtained water was tested in PVPSIT civil engineering department laboratory the test result was as fallows.

Table 1: Test Results of Purified Water Compared With Ground Water Samples

\begin{tabular}{|c|l|c|c|c|}
\hline S. No & \multicolumn{1}{|c|}{ Test Parameters } & $\begin{array}{c}\text { Desirable limit as per } \\
\text { IS10500:1991 }\end{array}$ & $\begin{array}{c}\text { Test Results Of } \\
\text { Ground Water } \\
\text { Sample }\end{array}$ & $\begin{array}{c}\text { Test Results Of } \\
\text { Purified Water } \\
\text { Sample }\end{array}$ \\
\hline 1 & Appearance & $\ldots \ldots$ & clear & clear \\
\hline 2 & Smell or Odor & Pleasant & Pleasant & Pleasant \\
\hline 3 & Taste & Pleasant & Pleasant & Pleasant \\
\hline 4 & pH Value & 6.5 to 8.5 & 7.51 & 7.31 \\
\hline 5 & Total Alkalinity, mg/l & 200 & 91 & 77 \\
\hline 6 & Acidity mg/l & 200 & 424 & 283 \\
\hline 7 & Total Solids, mg/l & 500 & 298 & 171 \\
\hline 8 & Total dissolved solids & 500 & 126 & 112 \\
\hline 9 & Total suspended solids & 500 & 143 & 106 \\
\hline 10 & Chlorides mg/l & 250 & 158 & 92 \\
\hline 11 & Total Hardness mg/l & 300 & & \\
\hline
\end{tabular}

\section{CONCLUSIONS}

Solar powered ultra-violate water purification system is made and the water is suitable for the purpose of drinking. The system provides sufficient potable water required for anormal sized family. The output of equipment is 35-40 liters of pure drinking water is obtained at a consumption of 2.4-3.6 watt-hour of power. If the project is implemented on large scale the drinking water scarcity in remote villages can be reduced to a greater extent.

\section{REFERENCES}

1. Seth Beachy, David Gallagher, Ben Barkley \& Jamison Swope,” Design of A Water Purification System” 2010.

2. Trupti N. Bhoskar, Prof. V. R. Ingle," Intelligent Energy Saving Control of UV lamp in water filter" International Journal of Scientific \& Engineering Research, Volume 5, Issue 7, ISSN 2229-5518July-2014.

3. Ichiro Kano, Daniel Darbouret and StéphaneMabic Research \& Development, Lab Water Division, Millipore, Saint-Quentinen-Yvelines, France” UV technologies in water purification systems” Journal of chromatography 2012.

4. Natasha Vermeulen,1Werden J. Keeler,2 Kanavillil Nandakumar,1 Kam Tin Leung1" The Bactericidal Effect of Ultraviolet and Visible Light on Escherichia coli” Article in Biotechnology and Bioengineering23 July 2007.

5. Steven H. Clarke, Environmental Engineer" Ultraviolet Light Disinfection in the Use of Individual Water Purification Devices"Agris: International Information System for The Agricultural Science and Technology, March 2006. 
6. Paul OnkundiNyangaresi, Yi Qin, Guolong Chen, Baoping Zhang, Yinghua Lu c, Liang Shen c, "ffects of single and combined UV-LEDs on inactivation and subsequent reactivation E. coli in water disinfection" journal homepage: www.elsevier.com/locate/watres8October 2018.

7. Piyush R. Panditrao, Chaitanya S. Bhalerao, Shekhar B. Bhor, Rupali S. Kad" Cost Effective Automated Water Filtration and Recycling System" International Journal of Advanced Research in Electrical, Electronics and Instrumentation Engineering Vol. 3, Issue 1, January 2014.

8. K.M. Johnson, M.R. Anil Kumar, P. Ponmurugan and B. MythiliGananamangai, " Ultraviolet Radiation and Its Germicidal Effect In Drinking Water Purification” Journal of Phytology Biotechnology, ISSN: 2075-6240, Jan 12010.

9. Mary H. Crawford, Michael A. Banas, Michael P. Ross, Douglas S. Ruby, Jeffrey S. Nelson, Ray Boucher, Andrew A. Allerman" Final LDRD Report: Ultraviolet Water Purification Systems for Rural Environments and Mobile Applications" Issued by Sandia National Laboratories, operated for the United States Department of Energy by Sandia Corporation November 2005.

10. Adegbola, AdedayoAyodele and Olaoye, Rebecca Adepate, "Investigating the Effectiveness of Ultraviolet (UV) Water Purification as Replacement of Chlorine Disinfection in Domestic Water Supply” International Journal of Engineering Science and Technology (IJEST) 08 August 2012.

11. A. Aissa-Bokhtachea, A. Zegaouia, B. Belmadania, MS. Bouchritb, "Water Purification by a lamp Discharge -Electronic Ballast System using a full bridge inverter" International Conference on Technologies and Materials for Renewable Energy, Environment and Sustainability, TMREES15 issues on 2015.

12. Mr. WadekarAbhijit Narayan, Mr. JadhavdnyaeshwarVittha, Mr. ZagadeNitin Vishnu, Mr. PasaleAbhay Narayan, Mr. GawadePrashant Sanjay, "Solar Power Operated Water Purifier Plant” International Journal Of Innovations in Engineering Research And Technology [IJIERT], ISSN: 2394-3696 2nd National Conference on Modern Trends in Electrical Engineering (NCMTEE-2K18) 30-31st March-2018.

13. ManojPhalak, PiyushKurkure, Nikhil Bhangale, VipulDeshmukh, MayurPatil, M H.Patil, "Solar Powered Reverse Osmosis Water Purifier" International Journal for Research in Engineering Application \& Management (IJREAM) ISSN : 2454 - 9150 Vol-03, Issue 01, Apr 2017.

14. Md. Z. H. Khan, Md. R. Al-Mamun, Suvash C. Majumder1, Md. Kamruzzaman "Water Purification and Disinfection by using Solar Energy: Towards Green Energy Challenge” Aceh International Journal of Science and Technology ISSN: 2088-9860 Journal homepage: http://jurnal.unsyiah.ac.id/aijst. December 31, 2015.

15. Anil K. Rajvanshi* and NoorieRajvanshi" Low-cost solar water purifier for rural households" Current Science General Articles, Vol. 115, No. 1, 10 July 2018.

16. Aaron Don M. Africa" A Rough Set Based Solar Powered Flood Water Purification System With A Fuzzy Logic Model” ARPN Journal of Engineering and Applied Sciences vol. 12, no. 3, February 2017.

17. Moa Megersa, AbebeBeyene, ArgawAmbelu, ZelekeAlebachew, and Ludwig Triest” Ethnomedicinal Knowledge on Water Purification in Selected Rural Areas of Ethiopia”, Ethnobotany Research and Applications (ISSN 1547-3465) is published online by the Department of Ethnobotany, Institute of Botany, Ilia State University 22 December 2015.

18. Deepak Devasagayam ,MayureshKathe, MayurPatil, NimishKavishwar" Solar Water Purifier" International Journal of Innovative Research in Advanced Engineering (IJIRAE) ISSN: 2349-2163 Volume 1 Issue 9 October 2014.

19. Naga SaradaSomanchia, Sri LalithaSwathiSagia,ThotakuraAshish Kumara, SaiPhanindra Dinesh Kakarlamudia , Ajay Parik”, Modelling and Analysis of Single Slope Solar Still at Different Water Depth”, International conference on water 
resources, coastal and ocean engineering (icwrcoe) 2015.

20. ShwetaChauhan, and K.C. Gupta, JyotiSingh, "Purification of Drinking Water with the Application of Natural Extracts”,Journal of Global Biosciences ISSN 2320-1355 Volume 4, Special Issue 1, 2015, pp. 1861-1866. 

